\title{
Stent-assisted balloon-induced intimal disruption and relamination of distal remaining aortic dissection after acute DeBakey type I repair
}

\author{
Elsa Madeleine Faure, MD, ${ }^{\text {a,b }}$ Salma El Batti, MD, PhD, ${ }^{\mathrm{a}}$ Willy Sutter, MD, ${ }^{\mathrm{a}}$ Alain Bel, MD, \\ Pierre Julia, MD, PhD, ${ }^{a}$ Paul Achouh, MD, PhD, ${ }^{a}$ and Jean-Marc Alsac, MD, PhD ${ }^{\mathrm{a}, \mathrm{c}}$
}

\section{ABSTRACT}

Objectives: Surgical repair in patients with acute DeBakey type I aortic dissection (ADIAD) achieves good short-term results, but in several patients the false lumen remains patent in the descending aorta because of distal intimal tears with persisting risk for distal aneurismal evolution. We report the short- and mid-term outcomes of the stent-assisted balloon-induced intimal disruption and relamination of aortic dissection (STABILISE) technique for the 16 first patients treated for a residual dissection of the descending thoracic aorta after repaired ADIAD.

Methods: We reviewed all patients treated with STABILISE for a remaining distal thoracoabdominal aortic dissection after ADIAD repair.

Results: From March 2016 to March 2018, 16 patients with previous surgery for ADIAD underwent the STABILISE procedure during the same hospitalization in a second-stage procedure to extend the repair within the descending thoracic aorta. The median age was 56 years (range, 43-65 years). Indication for the STABILISE procedure was persisting false lumen patency within the thoracic descending aorta associated with malperfusion symptoms in 13 patients and associated with dissecting aneurysm of the descending thoracic aorta $>40 \mathrm{~mm}$ in 3 patients. Technical success was achieved in 100\%. Eight (12.5\%) renal arteries required stenting during the procedure. In-hospital mortality was $6 \%$ $(\mathrm{n}=1)$. There was no stroke, spinal cord ischemia, ischemic colitis, or renal failure requiring dialysis. Median length of follow-up was 8 months (range, 3-24 months). One patient developed a proximal type 1 endoleak in the arch and required reintervention for proximal extension of the stent graft in zone 2. The primary visceral patency rate was $100 \%$. There were no late deaths reported. At last computed tomography scan, all patients had complete aortic remodeling of the treated thoracoabdominal aorta with no aortic enlargement.

Conclusions: The STABILISE technique, in patients with remaining distal thoracoabdominal aortic dissection at the acute stage of a type A repair, allowed an immediate remodeling of the thoracoabdominal aorta, which should improve their long-term outcomes in terms of aortic-related events. (J Thorac Cardiovasc Surg 2019;157:2159-65)

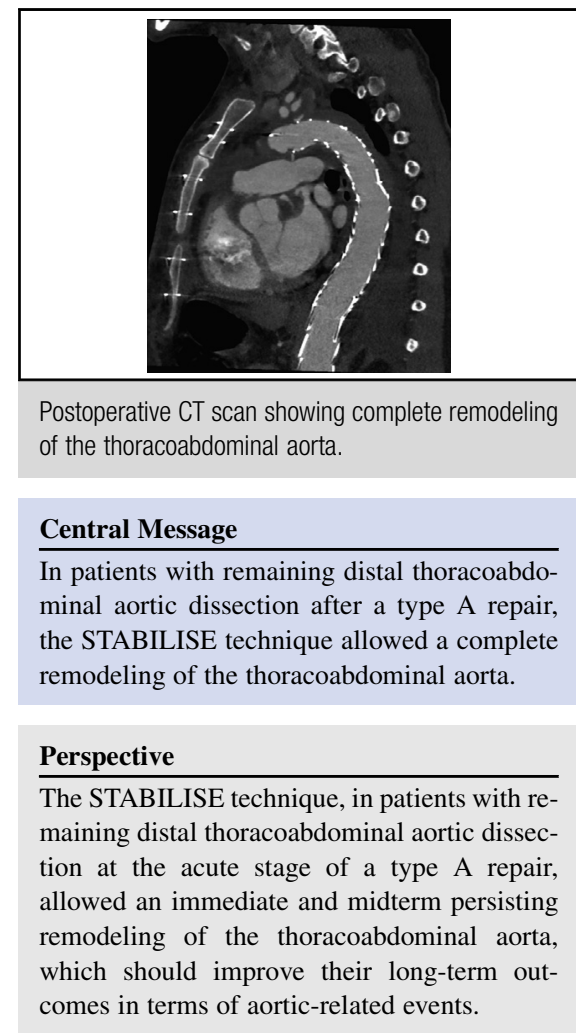

See Editorial Commentary page 2166.

\footnotetext{
From the ${ }^{a}$ Department of Cardiac and Vascular Surgery, Hôpital Européen Georges Pompidou, AP-HP, Paris, France; ${ }^{b}$ PhyMedExp, University of Montpellier, INSERM, CNRS, Montpellier, France; and ${ }^{\mathrm{c}}$ INSERM U970, Faculté de Médecine Paris-Descartes, Université Paris 5, Paris, France.

This work was supported by the Société de Chirurgie Vasculaire et Endovasculaire de Langue Française (SCVE).

Received for publication June 27, 2018; revisions received Oct 1, 2018; accepted for publication Oct 2, 2018; available ahead of print Nov 27, 2018.

Address for reprints: Elsa Madeleine Faure, MD, Service de Chirurgie Vasculaire et Endovasculaire, AP-HP Hôpital européen Georges-Pompidou (Paris), 20-40, rue Leblanc, 75908 Paris Cedex 15, France (E-mail: elsafaure@hotmail.com). $0022-5223 / \$ 36.00$

Copyright (c) 2018 by The American Association for Thoracic Surgery https://doi.org/10.1016/j.jtcvs.2018.10.031
}

The early survival of acute type A aortic dissection has significantly improved during the past 2 decades mainly

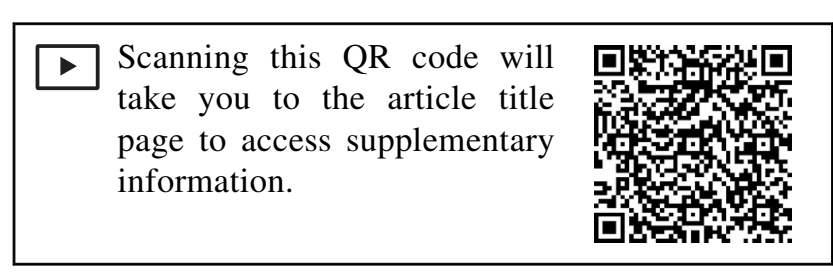




\begin{tabular}{|c|c|}
\hline Abbreviati & and Acronyms \\
\hline ADIAD & $\begin{aligned}= & \text { acute DeBakey type I aortic } \\
& \text { dissection }\end{aligned}$ \\
\hline $\mathrm{CT}$ & $=$ computed tomography \\
\hline STABIL & $\begin{aligned}= & \text { stent-assisted balloon-induced } \\
& \text { intimal disruption and relamination } \\
& \text { of aortic dissection }\end{aligned}$ \\
\hline ZDES & $=$ Zenith dissection endovascular stent \\
\hline
\end{tabular}

because of advances in diagnosis and surgical techniques. ${ }^{1-9}$ However, persistent patent false lumen in the thoracoabdominal aorta, which is a recognized factor for aortic growth, aortic rupture, and death, ${ }^{10-14}$ is frequently reported. Park and colleagues reported up to $89 \%$ of abdominal aorta false lumen patency after acute DeBakey type I aortic dissection (ADIAD) repair. ${ }^{13}$ Aneurysmal degeneration of the thoracoabdominal aorta is reported from $14.3 \%$ to $47.5 \%{ }^{13,14}$ and is the most frequent cause of reintervention, reported to be up to $86 \%$ by Kimura and colleagues. ${ }^{11}$ Therefore, achieving distal aortic remodeling when the proximal aorta has been repaired should improve long-term outcomes. The stent-assisted ballooninduced intimal disruption and relamination (STABILISE) technique was first described in 2014 by Hofferberth and colleagues on 11 patients ${ }^{15}$ to achieve false lumen elimination and immediately restore uniluminal thoracoabdominal aortic flow using balloon inflation of the aortic bare stent. We reported this technique on acute type B aortic dissection with such encouraging results regarding aortic remodeling $^{16,17}$ that in 2016 we started to develop this technique for remaining distal aortic dissection after ADIAD repair. The aim of this study was to report the early outcomes of the STABILISE technique on patients with remaining thoracoabdominal aortic dissection after surgical repair for ADIAD and to assess the mid-term outcomes on aortic remodeling and survival.

\section{METHODS}

The Georges Pompidou European Hospital Ethics Committee approved this retrospective study and waived the need for individual patient consent (CERHUPO 2015-10-03). All patients gave informed consent for each procedure.

\section{Study Population and Data Collection}

We performed a retrospective review of a prospective maintained database of acute aortic dissections in our department (database started in 2010), to identify all patients who underwent the STABILISE technique after previous open repair for ADIAD and during the initial hospitalization. ADIAD was defined as any dissection that involved the ascending and descending aorta appearing within 14 days of the onset of symptoms. The open repair for ADIAD included hemi, partial, or total arch replacement with frozen elephant trunk technique. The STABILISE technique was performed in a second-stage procedure at the early postoperative stage during the same hospitalization in patients who had persistent false lumen patency at the descending thoracic aorta level after open surgery associated with poor prognostic factors such as persistent or recurrent visceral malperfusion, or descending thoracic aortic diameter combining true and false lumen $>40 \mathrm{~mm}$ on postoperative control computed tomography (CT) scan. Conversely, exclusion criteria were: false lumen thrombosis at the descending thoracic aorta level after open surgery, dissection limited to the ascending aorta (or DeBakey type II), or persistent false lumen patency at the descending thoracic aorta level without poor prognostic factors (ie, without persistent or recurrent visceral malperfusion), or descending thoracic aortic diameter combining true and false lumen $<40 \mathrm{~mm}$ on postoperative control CT scan. Medical records were analyzed for preoperative patient characteristics, dissection morphology, details of operative strategy, intraoperative events, and postoperative course.

\section{Preoperative Management}

All patients had baseline CT scans with multiplanar reconstruction (Figure 1) after surgical repair and before the STABILISE procedure. It allowed assessing the result of the aortic surgery and the evolution of the false lumen distally such as patency, location of the primary entry tear, extension of the dissection, patency, and origin (true or false lumen) of visceral vessels.

\section{Operative Technique}

All procedures were performed using general anesthesia. All of the procedures but one were performed in a hybrid operating suite. The femoral artery side of insertion depended on the extension of the dissection within the aortic bifurcation and the iliac arteries and the side with the easier access to the true lumen was chosen. The operative technique was similar to that previously described for patients with acute type B aortic dissection. ${ }^{16,17}$

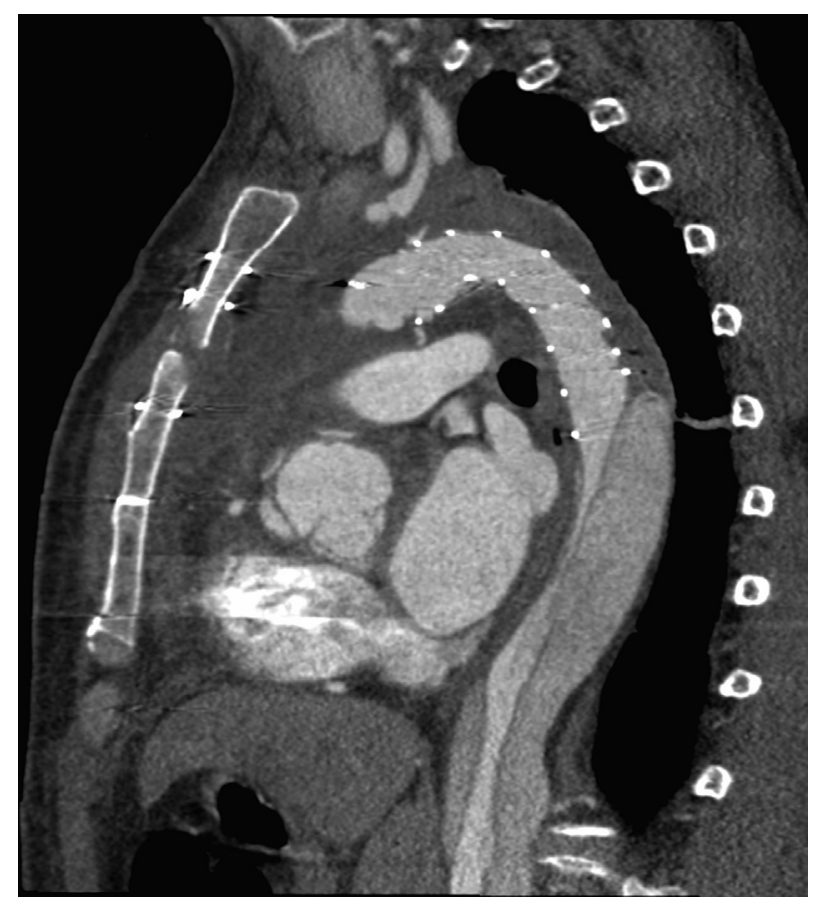

FIGURE 1. Preoperative computed tomography scan of a patient treated for an acute type A aortic dissection using total arch replacement with the frozen elephant trunk technique showing distal false lumen patency with true lumen narrowed by the false lumen. 


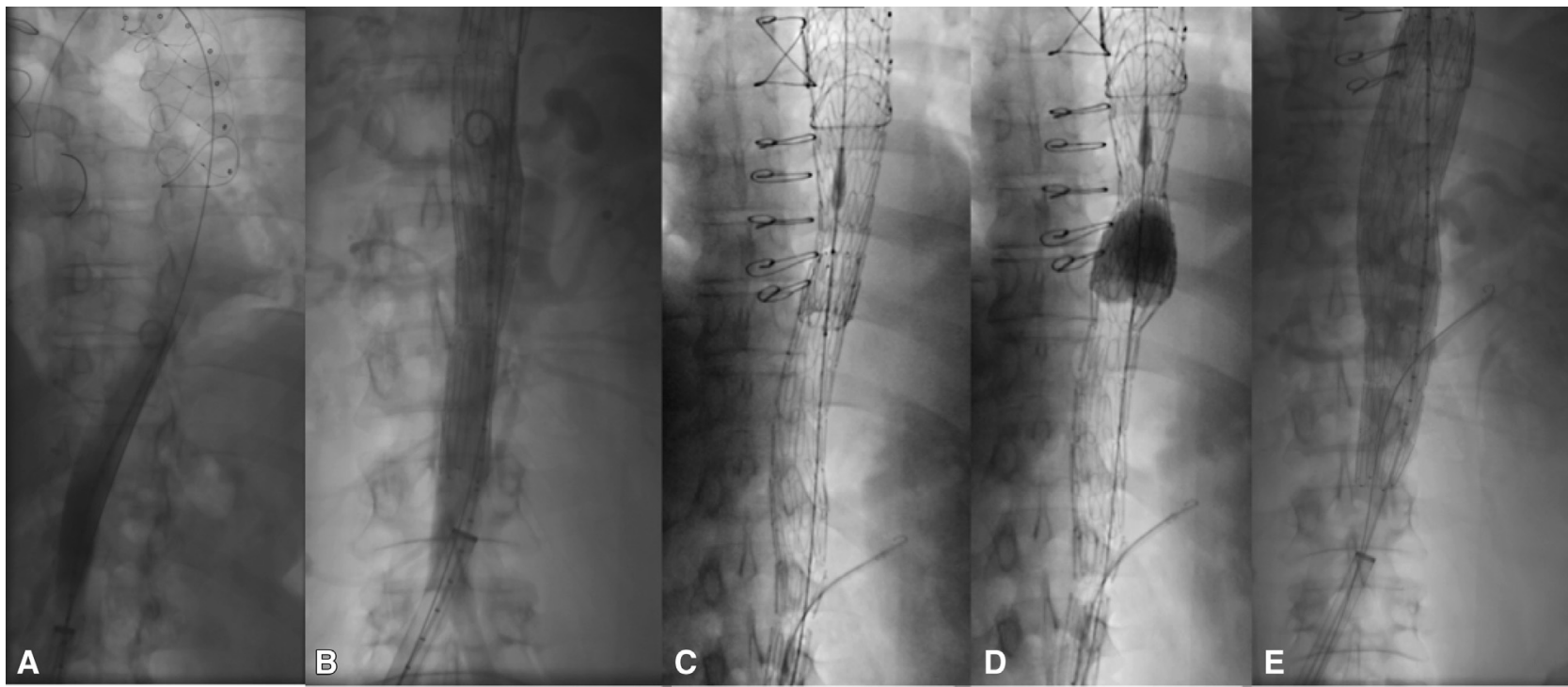

FIGURE 2. Perioperative imaging. A, Catheterization of the frozen elephant trunk; (B) controlled arteriography after stent graft and bare stent deployment before balloon inflation showing persistence of false lumen patency and left renal artery supplied by the false lumen. C and D, Balloon inflation of the bare stent after catheterization of the left renal artery through the mesh of the bare stent. E, Final arteriography showing complete remodeling of the aorta.

Proximal sealing. In case of total arch replacement combined with stented (or frozen) elephant trunk implantation (Thoraflex Hybrid, Vascutek Ltd, Glasgow, Scotland), the proximal stent graft was deployed in the stented elephant trunk with a minimum of $5 \mathrm{~cm}$ overlap (Figure 2, A). For all of the other ascending or hemiarch replacement the proximal stent graft was deployed in zone 2 or 3 to obtain sealing in the distal part of the arch. Diameter of the stent graft was sized on the basis of the proximal sealing zone in the arch, with a maximum of $20 \%$ of oversizing compared with native aorta or hybrid stent graft.

Distal sealing. Diameter of the stent graft was sized on the basis on the true and the false lumen at the level of the descending thoracic aorta. Because "off the shelf" stent grafts allow sealing of a maximum aortic diameter (combining true and false lumen) of $42 \mathrm{~mm}$ with their larger designs $(45-46 \mathrm{~mm})$, the distal part of the stent graft should land in an area where diameter does not exceed $42 \mathrm{~mm}$ on a $20-\mathrm{mm}$ length. The length of the stent graft should be adapted to fulfill this condition. In our experience, we mostly used $200-\mathrm{mm}$ stent grafts that could be extended up to $50 \mathrm{~mm}$ more distally to reach a suitable distal sealing zone and to preserve as many patent intercostal arteries as possible. Proximal stent graft coverage usually extends 100 to $150 \mathrm{~mm}$ above the coeliac trunk. If no adequate distal landing zone $\leq 42 \mathrm{~mm}$ could be reached above the coeliac trunk, the STABILISE technique should not be recommended.

Distal aortic bare stent deployment. The bare stent component is constructed of stacked Z-stents joined by polypropylene sutures, which can be deployed through a 16-French sheath (Figure 2, B). An angiogram at the level of the thoracoabdominal aorta was performed to serve as a road map. Delivery system of the Zenith Dissection Endovascular Stent (ZDES; Cook Medical, Bloomington, Ind) was then exchanged and advanced through the 24-French sheath, on the true lumen extra-stiff wire. Its optimal deployment should be aiming for a 1 -stent body overlap in the proximal stent graft, and an extension to the level of the infrarenal aorta. The ZDES 36-mm diameter was chosen for a maximum external aortic diameter up to $32 \mathrm{~mm}$, and the ZDES 46$\mathrm{mm}$ diameter for a maximum external aortic diameter between 32 and $42 \mathrm{~mm}$.

\section{Management of the Visceral Arteries Supplied by the False Lumen}

In cases of visceral or renal branches arising from the false lumen, or presenting signs of static malperfusion on preoperative CT scans, we recommend catheterizing the targeted vessels through the struts of the aortic bare stent, before its balloon expansion. This maneuver also allows access to the vessel for potential stenting after aortic bare stent dilatation. Balloon dilatation of the bare stent. Subsequently, a trilobe balloon catheter (C-TAG, W.L. Gore \& Associates [Flagstaff, Ariz]; large size for 26- to 42-mm aortic diameter) was inserted via the 24-French sheath on the Lunderquist extra-stiff wire (Figure 2, $C$-E). After accurate positioning at the level of the overlap zone between the distal end of the stent graft and the proximal end of ZDES, the balloon was manually inflated using fluoroscopic guidance. Balloon expansion in the stent graft was undertaken to the point of intimal flap disruption, leading to reapposition of the intimal flap to the aortic wall. Serial balloon dilatation of the stented true lumen was undertaken in the caudal direction to propagate the intimal flap disruption and simultaneously relaminate the intima to the aortic wall, all the way down to the infrarenal aorta. Balloon pressures ranged from 1 to 2 atmospheres with manual inflation to approximately $90 \%$ of total aortic size, to enable intimal disruption without applying this pressure to the outer aortic wall. On completion of balloon angioplasty, an angiogram was performed to ensure adequate proximal and distal seal of the false lumen, to assess false lumen obliteration, and branch vesse patency in the thoracoabdominal aorta. In cases of visceral or renal artery malperfusion, a bare stent can be deployed.

\section{RESULTS}

\section{Baseline Characteristics}

From March 2016 to March 2018, 102 patients underwent aortic repair for dissection involving the ascending aorta. Sixteen of them $(15.7 \%)$ who were treated for ADIAD had a STABILISE procedure during the same hospitalization in a second-stage procedure to extend the repair 


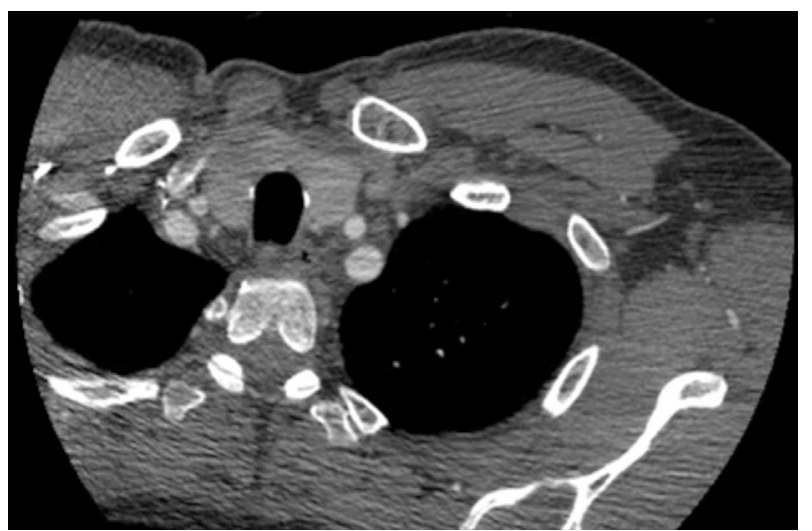

VIDEO 1. Preoperative computed tomography scan of a patient treated for an acute type A aortic dissection using total arch replacement with the frozen elephant trunk technique showing distal false lumen patency with true lumen narrowed by the false lumen. Video available at: https://www. jtcvs.org/article/S0022-5223(18)32783-1/fulltext.

within the descending thoracoabdominal aorta. Indication for the STABILISE procedure was persisting false lumen patency within the thoracic descending aorta associated with clinical and CT scan malperfusion symptoms in 13 patients (Video 1) and associated with dissecting aneurism of the descending thoracic aorta $>40 \mathrm{~mm}$ in 3 patients. In all patients large intimal tears were seen on the flap distally to the aortic segment repair within the descending thoracic aorta.

Twelve patients were male $(75 \%)$ and median age was 56 years (range, 43-65 years). Preoperative patient demographic characteristics, anatomic dissection characteristics, and selection for STABILISE are detailed in Table 1. All patients had American Society of Anesthesiologists physical status classification system 4 or 5 . None of them had Marfan syndrome.

\section{Procedural Outcomes}

All patients were treated for their ADIAD the day of the onset of the symptoms. The median interval from ADIAD repair to STABILISE procedure was 5 days (range, 1-19 days). Procedural details and outcomes are described Table 2. There was no preoperative cerebrospinal fluid drainage.

Proximal stent grafts used were C-TAG in all cases. Proximal anchoring of the stent graft was in a stented elephant trunk (Thoraflex hybrid, Vascutek Ltd) in 8 patients $(50 \%)$ and in zone 2 in 1 patient and in zone 3 in 7 patients. Median proximal stent graft diameter was $40 \mathrm{~mm}$ (range, 31-45 mm).

Median length of stent graft aortic coverage was 200 (range, 200-300) $\mathrm{mm}$. The distal end of the stent graft was located at the level of T8 in 1 patient, between T8 and T10 in 13 patients and at the level of T11 in 2 patients. Distally to the stent graft, one ZDES (Cook Medical) was
TABLE 1. Baseline patient demographic characteristics, anatomic dissection characteristics, and indication for STABILISE

\begin{tabular}{ll}
\hline \multicolumn{1}{c}{ Variable } & n (\%) \\
\hline Age, y & 56 \\
Female sex & $4(25)$ \\
Prior aortic surgery & $4(57)$ \\
$\quad$ Total arch repair and stented elephant trunk & $8(50)$ \\
Hemiarch replacement & $3(19)$ \\
Partial arch replacement & $5(31)$ \\
Anatomic dissection characteristics & \\
DeBakey type I & $16(100)$ \\
False lumen patency distal to the repair & $16(100)$ \\
Iliaque extension of the dissection & $16(100)$ \\
Visceral arteries supplied by false lumen or dissected & $27(42)$ \\
Indication for STABILISE & \\
Malperfusion & $13(81)$ \\
Maximum aortic diameter $>40$ mm & $3(19)$ \\
\hline
\end{tabular}

STABILISE, Stent-assisted balloon-induced intimal disruption and relamination of aortic dissection.

deployed. The distal end of the bare stent was in the infrarenal aorta in all patients, 3 to $4 \mathrm{~cm}$ below the renal arteries. In total 8 visceral arteries $(12.5 \%$ of all the visceral arteries) required stenting during the procedure in 7 patients $(44 \%)$. All stented arteries were renal arteries. All were dissected and/or supplied by the false lumen on preoperative CT scan. A total of 17 visceral arteries were dissected ( $\mathrm{n}=17$; stented: $\mathrm{n}=4 ; 24 \%$ ) or supplied by the false lumen ( $\mathrm{n}=10$; stented: $\mathrm{n}=4 ; 40 \%$ ).

One patient died during the end of the procedure. The procedure was performed the day after partial arch replacement because of persisting mesenteric and renal ischemia requiring dialysis despite aortic repair. An aortic rupture during the procedure was suspected even if there was no aortic rupture on the controlled angiography post balloon inflation. There was no other intraprocedural complication. At completion angiogram, all patients had a completely excluded false lumen at the stent grafted and bare-stented levels (from the arch to infrarenal aorta), no endoleak was detected, and there was no aortic or branch vessel injury.

\section{Early (<30 Days) Outcomes}

There were no other postoperative deaths, no neurologic events such as stroke or spinal cord ischemia and no ischemic colitis or renal failure requiring dialysis. Early mortality rate was $6 \%(n=1)$.

\section{Midterm (>30 Days) Outcomes}

The median length of follow-up was 8 (range, 3-24) months. There were no patients lost to follow-up. One patient developed a proximal type 1 endoleak and required reintervention. He had initial proximal anchoring in zone 3 in native aorta and required proximal extension of the stent 
TABLE 2. Procedural details and outcomes

\begin{tabular}{|c|c|c|c|c|c|c|c|c|c|c|}
\hline Patient number & Age, years & Sex & $\begin{array}{l}\text { Proximal } \\
\text { repair }\end{array}$ & Time, days* & $\begin{array}{l}\text { C-TAG } \\
\text { size }\end{array}$ & ZDES size & $\begin{array}{c}\text { Aortic branch } \\
\text { stenting }\end{array}$ & $\begin{array}{c}\text { Reintervention, } \\
\text { days }\end{array}$ & $\begin{array}{c}\text { Death, } \\
\text { days }\end{array}$ & $\begin{array}{c}\text { Follow-up, } \\
\text { days }\end{array}$ \\
\hline 1 & 43 & $\mathrm{~m}$ & TAR & 8 & 31 & 46-185 & - & $\mathrm{n}$ & $\mathrm{n}$ & 734 \\
\hline 2 & 65 & $\mathrm{~m}$ & TAR & 1 & 45 & 46-185 & - & $\mathrm{n}$ & $\mathrm{n}$ & 727 \\
\hline 3 & 55 & $\mathrm{~m}$ & PAR & 12 & 45 & 46-185 & - & $\mathrm{n}$ & $\mathrm{n}$ & 202 \\
\hline 4 & 63 & $\mathrm{~m}$ & TAR & 4 & 45 & 46-185 & LRA & $\mathrm{n}$ & $\mathrm{n}$ & 718 \\
\hline 5 & 45 & $\mathrm{~m}$ & TAR & 14 & 37 & 46-185 & LRA & $\mathrm{n}$ & $\mathrm{n}$ & 353 \\
\hline 6 & 54 & $\mathrm{~m}$ & HAR & 2 & 37 & 46-185 & LRA & $\mathrm{n}$ & $\mathrm{n}$ & 538 \\
\hline 7 & 57 & $\mathrm{~m}$ & PAR & 16 & 40 & $46-185$ & - & $\mathrm{n}$ & $\mathrm{n}$ & 462 \\
\hline 8 & 67 & $\mathrm{~m}$ & TAR & 9 & 37 & 46-185 & LRA, RRA & $\mathrm{n}$ & $\mathrm{n}$ & 515 \\
\hline 9 & 51 & $\mathrm{f}$ & PAR & 3 & 40 & 46-185 & LRA & $\mathrm{n}$ & $\mathrm{n}$ & 243 \\
\hline 10 & 49 & $\mathrm{f}$ & PAR & 5 & 34 & $36-180$ & - & $\mathrm{n}$ & $\mathrm{n}$ & 121 \\
\hline 11 & 58 & $\mathrm{f}$ & HAR & 4 & 37 & 46-185 & LRA & $\mathrm{n}$ & $\mathrm{n}$ & 96 \\
\hline 12 & 46 & $\mathrm{~m}$ & HAR & 5 & 40 & 46-185 & - & $\mathrm{n}$ & $\mathrm{n}$ & 109 \\
\hline 13 & 65 & $\mathrm{f}$ & TAR & 2 & 34 & 36-180 & - & EL Ia (143) & $\mathrm{n}$ & 95 \\
\hline 14 & 53 & $\mathrm{~m}$ & TAR & 6 & 40 & $46-185$ & LRA & $\mathrm{n}$ & $\mathrm{n}$ & 151 \\
\hline 15 & 61 & $\mathrm{~m}$ & PAR & 1 & 45 & $46-185$ & - & $\mathrm{n}$ & $\mathrm{y}(0)$ & - \\
\hline 16 & 59 & $\mathrm{~m}$ & TAR & 19 & 40 & $46-185$ & - & $\mathrm{n}$ & $\mathrm{N}$ & 90 \\
\hline
\end{tabular}

C-TAG proximal stent graft from W.L. Gore \& Associates, Inc (Flagstaff, Ariz). Zenith Dissection Endovascular Stent (ZDES) from Cook Medical (Bloomington, Ind). $m$, Male; $T A R$, total arch replacement and frozen (stented) elephant trunk; $n$, no; PAR, partial arch replacement; $L R A$, left renal artery; HAR, hemiarch replacement; RRA, right renal artery; $f$, female; $E L$, endoleak. *Time from open aortic repair to STABILISE procedure.

graft in zone 2 with left subclavian artery transposition. There were neither other endoleaks nor reinterventions, giving a reintervention rate of $6 \%(n=1)$. Primary visceral

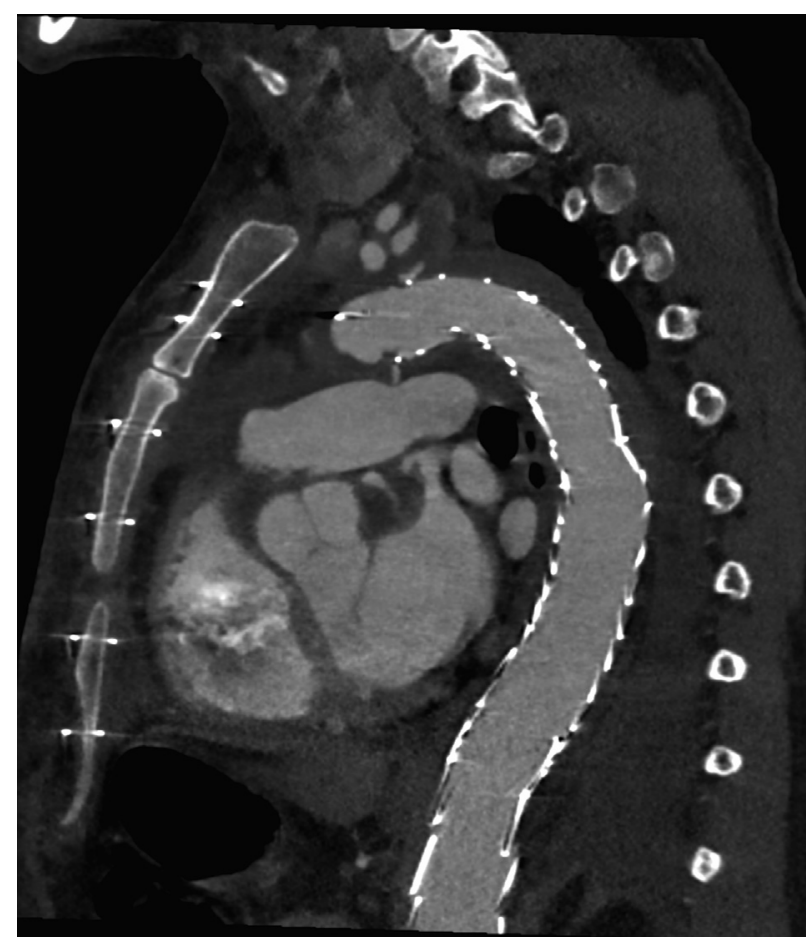

FIGURE 3. Two years postoperative computed tomography scan of the same patient in Figure 1 showing complete remodeling of the thoracoabdominal aorta. patency rate was $100 \%$. There were no late deaths reported during this period giving a total mortality rate of $6 \%$.

\section{Aortic Remodeling}

At last CT scan, all of the patients had complete aortic remodeling at the stent graft level with complete false lumen thrombosis and cicatrization (Figure 3, Video 2). At the bare stent level 14 patients $(94 \%)$ had complete aortic remodeling and cicatrization. One patient had a remaining short segment of patent false lumen at the visceral level due to incomplete bare stent deployment to the external aortic wall: no enlargement was seen at 12 months at this level

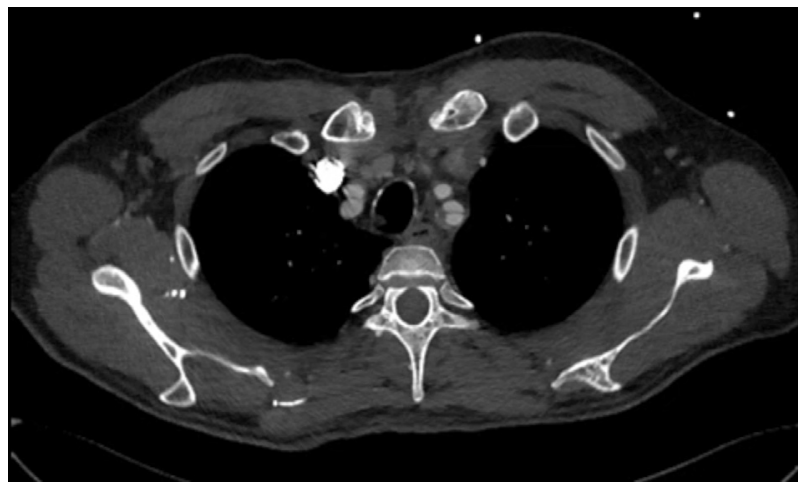

VIDEO 2. Postoperative computed tomography scan showing complete remodeling of the thoracoabdominal aorta. Video available at: https:// www.jtcvs.org/article/S0022-5223(18)32783-1/fulltext. 
in this patient. Distally, at the unstented infrarenal aortoiliac level, 2 patients (13\%) had complete aortic remodeling, and the other 13 had persistent false lumen flow with all stable aortoiliac diameters.

\section{DISCUSSION}

We report mid-term results of the first series of patients treated for remaining thoracoabdominal dissection after ADIAD repair using the already described STABILISE technique for type B dissection. ${ }^{15-18}$ In this study the STABILISE technique led to an immediate and extensive remodeling of the thoracoabdominal aorta with intimal flap delamination, which probably reduced the risk for aortic growth in the most critical part of the aorta: the thoracic descending and visceral part. The late prognosis of patients after type A repair is mainly related to the condition of the aorta distal from the site of repair. Persistent false lumen patency was reported from $59 \%{ }^{4}$ to $86 \%{ }^{13}$ in the abdominal aorta after ADIAD repair, and has been reported as a risk factor for aortic growth, reintervention, and mortality in several studies. ${ }^{10-14}$

Barron and colleagues ${ }^{19}$ reported that $25 \%$ of the patients with persistent distal false lumen after type A repair developed a distal aortic aneurism $>5 \mathrm{~cm}$ during their follow-up. Park and colleagues ${ }^{13}$ reported that persistent distal false lumen patency is a risk factor for chronic aortic dilatation after type A repair, as well as Tamura and colleagues. ${ }^{20}$ Thus, achieving positive remodeling at an extended thoracoabdominal level at the acute stage in all patients will probably improve their long-term outcomes.

The results of STABILISE for remaining thoracoabdominal dissection after ADIAD repair were similar than those previously reported for patients with primary acute type $\mathrm{B}$ aortic dissection. ${ }^{16}$ It was to be expected that the early results of the technique did not differ for both pathologies because patients were treated at the same stage of the dissection. However, at the acute stage of a type A dissection, even after successful proximal aortic repair, the patients usually had a more severe physical status than patients with primary acute type B dissection. In this study all patients had American Society of Anesthesiologists physical status classification system 4 or 5 . This unstable status of the patients could generate more complications such as paraplegia, and renal failure requiring dialysis after the STABILISE procedure; that was not the case in this study.

Regarding the long-term outcomes of the technique, the natural course of remaining thoracoabdominal dissection after ADIAD repair and primary type B aortic dissection has been reported to represent 2 distinct pathophysiological entities with different late outcomes. ${ }^{21}$ For example, if primary entry tear and false lumen thrombosis were more frequent in patient with acute ADIAD repair than in patients with primary type $\mathrm{B}$ dissection, it has been reported that when the primary entry tear was not thrombosed, patients with remaining thoracoabdominal dissection after ADIAD repair had a higher risk of reintervention for aneurismal evolution than for patients with primary type B dissection. ${ }^{21}$ Therefore, the longterm results of the STABILISE technique need to be assessed separately between these patients and the late potential benefit of the technique could be more obvious in patients after ADIAD repair. In this way Esposito and colleagues reported that hybrid repair of acute type A aortic dissections with the Lupiae technique, which consisted of a Dacron landing zone on the distal arch followed by thoracic endovascular aortic repair of any residual intimal tear refilling a patent false lumen extension, seems to be associated with a high probability of false lumen thrombosis and low rates of reoperations on the distal aorta on a 10 -year period. ${ }^{22}$

In this study all patients treated presented a persistent distal false lumen despite total arch replacement and frozen elephant trunk. The efficacy of endovascular repair on residual intimal tear or distal new entry after frozen elephant trunk for ADIAD was already reported by Pan and colleagues. ${ }^{23}$ In their study $2.3 \%$ of the patients treated with frozen elephant trunk required more extensive treatment in the descending thoracic aorta.

Visceral branches required stenting in $12.5 \%$, which is quite similar to the $9 \%$ reported for primary type B dissection. ${ }^{16}$ As previously reported, ${ }^{16,17}$ all stented branches were dissected or supplied by the false lumen, and renal arteries were most frequently involved. Six of the 7 patients who required renal artery stenting had actually previous renal malperfusion on CT scan performed after proximal aortic repair and before the STABILISE procedure, meaning that without the procedure they might have lost their kidney. There was no stenting failure through the mesh of the bare stent when required, and none of the visceral branches were lost. Primary patency after stenting was $100 \%$.

One patient died at the end of the procedure. We suspected an aortic rupture during the procedure even if there was no aortic rupture on the controlled angiography post balloon inflation. Another hypothesis was that a sudden washout of metabolites of previously obstructed circulations contributed to his cardiac arrest. This emergent procedure was the first and only performed in a standard operative room condition, unlike in a hybrid operating suite, without the use of CT angiography-fluoroscopy fusion imaging during balloon inflation. We assume that these complex aortic endovascular procedures should be performed in a hybrid operating suite, which allowed better visualization of the nominal aortic diameter and might prevent against overinflation of the balloon. 


\section{Limitation}

This is a small cohort of patients without a control group and long-term follow-up is missing. Other studies with larger population and longer follow-up are needed.

\section{CONCLUSIONS}

Our results suggest that the STABILISE technique in patients with remaining thoracoabdominal dissection after ADIAD repair allowed an immediate and mid-term persisting remodeling of the thoracoabdominal aorta, which should improve their long-term outcomes in terms of aortic-related adverse events. Longer follow-up in larger studies are needed to better determine the beneficial role of STABILISE for these patients.

\section{Conflict of Interest Statement}

Authors have nothing to disclose with regard to commercial support.

\section{References}

1. Crawford SE. The diagnosis and management of aortic dissection. JAMA. 1990; 262:2537-41.

2. Stevens LM, Madsen JC, Isselbacher EM, Khairy P, MacGillivray TE, Hilgenberg AD, et al. Surgical management and long-term outcomes for acute ascending aortic dissection. J Thorac Cardiovasc Surg. 2009;138:1349-57.

3. Chikwe J, Cavallaro P, Itagaki S, Seigerman M, Diluozzo G, Adams DH. National outcomes in acute aortic dissection: influence of surgeon and institutional volume on operative mortality. Ann Thorac Surg. 2013;95:1563-9.

4. Omura A, Miyahara S, Yamanaka K, Sakamoto T, Matsumori M, Okada K, et al. Early and late outcomes of repaired acute DeBakey type I aortic dissection after graft replacement. J Thorac Cardiovasc Surg. 2016;151:341-8.

5. Easo J, Weigang E, Hölzl PP, Horst M, Hoffmann I, Blettner M, et al; GERAADA study group. Influence of operative strategy for the aortic arch in DeBakey type I aortic dissection: analysis of the German Registry for Acute Aortic Dissection Type A. J Thorac Cardiovasc Surg. 2012;144:617-23.

6. Tsai TT, Evangelista A, Nienaber CA, Trimarchi S, Sechtem U, Fattori R, et al. International Registry of Acute Aortic Dissection (IRAD). Long-term survival in patients presenting with type A acute aortic dissection: insights from the International Registry of Acute Aortic Dissection (IRAD). Circulation. 2006;114: I350-6.

7. Cabasa A, Pochettino A. Surgical management and outcomes of type A dissection-the Mayo Clinic experience. Ann Cardiothorac Surg. 2016:5:296-309.

8. Nishida H, Tabata M, Fukui T, Sato Y, Kin H, Takanashi. A systematic approach to improve the outcomes of type A aortic dissection. J Thorac Cardiovasc Surg. 2017;154:89-96.
9. Olsson C, Ahlsson A, Fuglsang S, Geirsson A, Gunn J, Hansson EC. Mediumterm survival after surgery for acute Type A aortic dissection is improving Eur J Cardiothorac Surg. 2017;52:852-7.

10. Fattouch K, Sampognaro R, Navarra E, Caruso M, Pisano C, Coppola G, et al Long-term results after repair of type a acute aortic dissection according to false lumen patency. Ann Thorac Surg. 2009;88:1244-50.

11. Kimura N, Itoh S, Yuri K, Adachi K, Matsumoto H, Yamaguchi A, et al. Reoperation for enlargement of the distal aorta after initial surgery for acute type A aortic dissection. J Thorac Cardiovasc Surg. 2015;149:91-8.e1.

12. Halstead JC, Meier M, Etz C, Spielvogel D, Bodian C, Wurm M, et al. The fate of distal aorta after repair of acute type A aortic dissection. J Thorac Cardiovasc Surg. 2007; 133:127-35

13. Park KH, Lim C, Choi JH, Chung E, Choi SI, Chun EJ, et al. Midterm change of descending aortic false lumen after repair of acute type I dissection. Ann Thorac Surg. 2009;87:103-8.

14. Leontyev S, Haag F, Davierwala PM, Lehmkuhl L, Borger MA, Etz CD, et al Postoperative changes in the distal residual aorta after surgery for acute type A aortic dissection: impact of false lumen patency and size of descending aorta. Thorac Cardiovasc Surg. 2017;65:90-8.

15. Hofferberth SC, Nixon IK, Boston RC, McLachlan CS, Mossop PJ. Stent-assisted balloon-induced intimal disruption and relamination in aortic dissection repair: the STABILISE concept. J Thorac Cardiovasc Surg. 2014;147:1240-5.

16. Faure EM, El Batti S, Abou Rjeili M, Julia P, Alsac JM. Midterm outcomes of stent-assisted balloon-induced intimal disruption and relamination in aortic dissection repair (STABILISE) in acute type B aortic dissection. Eur J Vasc Endovasc Surg. 2018;56:209-15.

17. Faure EM, El Batti S, Abou Rjeili M, Ben Abdallah I, Julia P, Alsac JM. Stentassisted, balloon-induced intimal disruption and relamination of aortic dissection in patients with Marfan syndrome: midterm outcomes and aortic remodeling. $J$ Thorac Cardiovasc Surg. 2018;156:1787-93.

18. Melissano G, Bertoglio L, Rinaldi E, Mascia D, Kahlberg A, Loschi D, et al Satisfactory short-term outcomes of the STABILISE technique for type B aortic dissection. J Vasc Surg. 2018;68:966-75.

19. Barron DJ, Livesey SA, Brown IW, Delaney DJ, Lamb RK, Monro JL. Twenty year follow-up of acute type a dissection: the incidence and extent of distal aortic disease using magnetic resonance imaging. J Card Surg. 1997;12:147-59.

20. Tamura K, Chikazawa G, Hiraoka A, Totsugawa T, Sakaguchi T, Yoshitaka H The prognostic impact of distal anastomotic new entry after acute type I aortic dissection repair. Eur J Cardiothorac Surg. 2017;52:867-73.

21. Krähenbühl E, Maksimovic S, Sodeck G, Reineke D, Schoenhoff F, Schmidli J, et al. What makes the difference between the natural course of a remaining type B dissection after type A repair and a primary type B aortic dissection? Eur J Cardiothorac Surg. 2012;41:e110-5; discussion: e115-6.

22. Esposito G, Cappabianca G, Bichi S, Cricco A, Albano G, Anzuini A. Hybrid repair of type A acute aortic dissections with the Lupiae technique: ten-year results. J Thorac Cardiovasc Surg. 2015;149:S99-104.

23. Pan XD, Li B, Ma WG, Zheng J, Liu YM, Zhu JM, et al. Endovascular repair of residual intimal tear or distal new entry after frozen elephant trunk for type A aortic dissection. J Thorac Dis. 2017;9:529-36.

Key Words: aortic dissection, TEVAR, STABILISE 